\begin{tabular}{|c|c|}
\hline Title & Hierarchical classification of land use types using multiple vegetation indices to measure the effects of urbanization \\
\hline Author(s) & Shishir, Sharmin; Tsuyuzaki, Shiro \\
\hline Citation & $\begin{array}{l}\text { Environmental monitoring and assessment, 190(6), } 342 \\
\text { https://doi.org/10.1007/s10661-018-6714-3 }\end{array}$ \\
\hline Issue Date & $2018-06$ \\
\hline DOC URL & http:/hdl.handle.net/2115/74518 \\
\hline Rights & The final publication is avail lable at link.springer.com \\
\hline Type & article (author version) \\
\hline Additional Information & There are other files related to this item in HUSCAP. Check the above URL. \\
\hline File Information & EMAS-D-17-03605_Revised_manuscript -.pdf \\
\hline
\end{tabular}

Instructions for use 


\section{Hierarchical classification of land use types using multiple vegetation 2 indices to measure the effects of urbanization}

3 Sharmin Shishir ${ }^{\mathrm{a} *}$ and Shiro Tsuyuzaki ${ }^{\mathrm{b}}$

$4 \quad{ }^{\mathrm{a}}$ Graduate School of Environmental Science, Hokkaido University, Sapporo, 060-0810, Japan.

5 braduate School of Environmental Earth Science, Hokkaido University, Sapporo, 060-0810, Japan.

6 ORCID: 0000-0003-3010-8699

$7 \quad *$ Corresponding author: Sharmin Shishir $(\bowtie)$

8 Graduate School of Environmental Science, Hokkaido University, N-10 W-5, North Ward, 060-

9 0810, Sapporo, Japan. tel: +81-11-706-2282, fax: +81-11-706-4954,

10 e-mail: s_shishir@eis.hokudai.ac.jp.

11 ORCID: 0000-0003-4094-7242

12

13

\section{Introduction}

Since the construction of new towns within natural ecosystems can cause the rapid deterioration of endangered and threatened ecosystems and landscape diversities therein, it is necessary to predict the effects of land use changes to promote the conservation and restoration of ecosystems prior to urbanization. Fine-resolution data are desirable for detecting land use changes as a result of urbanization; accordingly, the resolution of land use maps should be sufficiently fine for detecting the effects of road networks and of related human impacts on adjacent areas (Nigam 2000; Erener et al. 2012; Akay and Sertel 2016). 
However, due to the lack of high-resolution data, such detailed analyses are scarce (Fonji and

Taff 2014; Kalyani and Govindarajulu 2015). Two satellites, namely, IKONOS and

WorldView-2 (WV2), recently provided high-resolution data with a resolution of less than 1 m (Aguilar et al. 2013). Such a resolution is likely to be suitable for analyzing land use changes caused by urbanization (Nouri et al. 2014), although the effectiveness of these datasets has not been examined. Therefore, the prime objective of the present study is to validate the applicability of these high-resolution satellite data to the detection of land use changes caused by urbanization.

The vegetation index (VI) was developed to detect the characteristics of vegetation and land use via the combination of two or more wavelength bands related to photosynthesis, i.e., the blue, green, red and near-infrared bands (Huete et al. 1999). A high VI indicates a high vegetation greenness related to the high activities and low stresses of plants, and vice versa (Rocha and Shaver 2009). Therefore, VIs are often applied to analyses of land use and vegetation changes, e.g., to detect spatial variabilities (Matsushita et al. 2007), plant cover distributions and densities (Myneni et al. 1997; Saleska et al. 2007) and temporal changes (Lunetta et al. 2006). To evaluate the greenness of the ground surface, various VIs have been proposed (Joshi and Chandra 2011; Barzegar et al. 2015), and they are represented by the normalized difference vegetation index (NDVI), enhanced vegetation index (EVI), two-band enhanced vegetation index (EVI2) and green-red vegetation index (GRVI) (Jiang et al. 2007). The NDVI is widely used to detect land use-land cover (LULC) changes (Sahebjalal and Dashtekian 2013; Singh et al. 2016). Additionally, measurements of the NDVI are employed to broadly assess the spatiotemporal characteristics of LULC, including the vegetation cover (Kinthada et al. 2014). The principle of the NDVI is derived from the reflectance characteristics of photosynthesis, i.e., through an examination of the vegetation 
reflected by plants (Rouse et al. 1974). The weakness of this index lies in the fact that atmospheric and/or ground surface conditions, such as clouds and soils, often distort its accuracy (Kushida et al. 2015; Miura et al. 2001). Three indices, namely, the EVI, EVI2 and GRVI, were developed to reduce these obstacles, and they are popularly employed in addition to the NDVI (Phompila et al. 2015). The EVI enhances the greenness signal of the ground surface, which includes forest canopy structures, by using the blue band (Huete et al. 2002) and therefore reduces soil and atmospheric interference (Holben and Justice 1981). The EVI2 was modified from the EVI by removing the blue band to improve the auto-correlative defects of surface reflectance spectra between the red and blue wavelengths (Jiang et al. 2008), particularly when the background soil reflectance fluctuates (Kushida et al. 2015). The GRVI is often applied to evaluate forest degradation and canopy tree phenology, because this index is sensitive to changes in the leaf color at the canopy surface by using green wavelengths (Motohka et al. 2010).

The effectiveness of each of the abovementioned VIs has been compared well at coarse scales, e.g., at $30 \mathrm{~m}$ with Landsat TM5 data and at $250 \mathrm{~m}$ with both MOD13Q1 and NOAA-AVHRR imagery (Julien et al. 2011). However, only a few studies have been conducted to investigate LULC changes using VI time series (Markogianni et al. 2013). Land use classification schemes using VIs at a fine scale should be validated prior to examining land use changes, because the accuracies of these VIs at higher resolutions have not been examined thoroughly. A new planned township, namely, Purbachal New Town, is being prepared on the northeastern side of Dhaka, Bangladesh (Rahman et al. 2016a). Highresolution data are available for a land use comparison between the pre- and posturbanization periods. Therefore, the effectiveness of each of the four popular vegetation indices, namely, the EVI2, EVI, GRVI and NDVI, were examined at a high resolution by comparing the two phases of urbanization (i.e., pre-urbanization and present-day) in the new 
township. Each VI has both strong and weak points with regard to the classification of land use types (Dibs et al. 2017). To solve this issue, a decision tree (DT) was also utilized in this study. The application of DTs has been increased for image classification purposes because of their accuracy and interpretation capabilities. DTs are effective for categorizing and selecting each class in a classification tree (Laliberte et al. 2007), and they have performed successfully with remotely sensed data for the analysis of land use changes at coarse resolutions (Brown de Colstoun et al. 2003, Sesnie et al. 2008), although their accuracy was not examined for fine resolutions (high-resolution satellite imagery $<30 \mathrm{~m}$ and very highresolution $\leq 5 \mathrm{~m}$ ) (Fisher et al. 2017).

The first objective in this study was to examine the efficiencies of the VIs with regard to land use classification at a fine scale, because their efficiencies may differ between coarse and fine resolutions. The second objective was to characterize the VIs for each land type and to develop a hierarchical classification using a DT utilizing the characteristics of the examined VIs. Finally, the third objective was to characterize the land use changes induced by urbanization.

\section{Materials and methods}

\section{Study area}

Purbachal New Town, Bangladesh (2349'45.53"-2352'30.72"N and 90²8'20.18"$90^{\circ} 32 ' 43.26 " E$ ) was selected as the study area (Figure 1). At a large scale, Purbachal New Town is located within eastern-central Bangladesh between large floodplains (i.e., the Old Brahmaputra Floodplains) and terraces and is sandwiched by two rivers, namely, the Balu and Sitalakkhya Rivers, on the west and east sides. The maximum mean monthly temperature is $26.3^{\circ} \mathrm{C}$ in August, and the minimum is $12.7^{\circ} \mathrm{C}$ in January (Shapla et al. 2015). The annual 
precipitation is $2,030 \mathrm{~mm}$. The dry season generally ranges from December to February, and the rainy season lasts from June to September (Rahman et al. 2016b). The new town project was established to reduce the overpopulation in the capital city of Dhaka, the population density of which was $57,167 / \mathrm{km}^{2}$ in 2011 (Khatun et al. 2015). The planned area of the new town is 2,489 ha (Zaman 2016). The construction started in 1995, and it did not cease until 2015. Prior to urbanization, the major land use types were forest (Shorea robusta Gaertner f., in the Dipterocarpaceae family, locally called Sal forest), homestead, homestead vegetation, cropland, and various others (Rahman et al. 2016a).

The expansion of urban areas in Bangladesh was inadequately planned and controlled due to truncated laws (Hossain 2013). Per the Environmental Conservation Act of 1995 and the Bangladesh Environmental Conservation Rules, 1997, the preservation of natural forests and privately owned commercial forests dominated by Shorea robusta should take priority during the land development planning of Purbachal New Town. The major forest products are edible fruits, timber and medicines. These preserved forests are expected to sustain endemic and/or invaluable flora and fauna, although land development activities often neglect these perspectives (Zaman 2016). Although the emphasis during the pre-planning stage was the in situ preservation of entire forests, the idea to maintain all of the patches of Shorea forest was later rejected because those isolated patches had already been exposed to human activities. To compensate for the loss of forested area, a green belt with a width of $15 \mathrm{~m}$ to be produced through afforestation was planned for the full perimeter of the township area $\left(24.2 \mathrm{~km}^{2}\right)$ with a few exceptions. There were no interferences with the natural drainage systems that had maintained the pristine ecosystems in the region.

In total, the land use types of the study area were classified into eight categories (Table 4). Of those land use types, native forests with a maximum height of $36 \mathrm{~m}$ dominated by Shorea robusta have maintained the highest biodiversity, and they contain numerous 
endangered species (Gautam et al. 2006; Mandal et al. 2013). Therefore, the accurate detection of the distribution of Shorea forest was the priority for this land use analysis. The other land use types were homestead (i.e., settlement and residential areas), homestead vegetation (vegetation consisting of trees, shrubs and herbs on and around the settlement), cropland, grassland, agricultural low land, bare land and water bodies. In general, therefore, homestead vegetation is larger than homestead. The homestead vegetation and agricultural low land types also support a high biodiversity (Hasnat and Hoque 2016). Currently, the forest ecosystems in the region are decreasing rapidly due to economical demands and human interferences, such as overexploitation, deforestation, excessive trash buildup and encroachment (Salam et al. 1999; Hassan 2004). Among the artificial land use types, cropland, the major products of which are rice, jute and vegetables (e.g., cultivars consisting of gourds, beans, cabbage, cauliflower and tomatoes), was distributed broadly prior to urbanization (Shapla et al. 2015).

\section{IKONOS and WV2 data}

The data were obtained from the satellite imagery of IKONOS at 04:35 (GMT) on May 1, 2001, and at 04:44 on February 16, 2002, prior to urbanization and from WV2 imagery at 04:41 on December 9, 2015 (Digital Globe - Apollo Mapping, Longmont, Colorado, USA) at present stage, since IKONOS terminated data acquisition after 2014 and WV started data collection in October 2009. The resolutions of the IKONOS and WV2 sensors are $0.8 \mathrm{~m}$ (true color) and $0.5 \mathrm{~m}$ (natural color), respectively. All of the images were devoid of clouds. These remote sensing data were integrated via ArcGIS (version 10.2). Integrated analyses were conducted after checking the quality of the pre-processed data to remove noise and unify the georeferences. These images were re-projected onto the Bangladesh Transverse 
Mercator (BTM) projection to record the statistics of landscape changes, because of the projected coordinate system in Bangladesh (Dewan and Yamaguchi 2009).

143 Evaluation of the vegetation indices and hierarchical classification

144 The categories of land use types were matched with the land use map published by the Ministry of Housing and Public Works of Bangladesh (Anonymous 2013) with a few modifications adjusted to recently developed land use patterns. The modification was made by establishing three land use types, cropland, grassland and bare land, all of which were cultivable land in the original map (Anonymous 2013). Because the map was manufactured based on various datasets consisting of topographical, geographical and historical data at a fine scale, this map was utilized as a reference during the evaluation of land use classifications.

A total of eleven VIs was investigated to confirm the accuracy of land use change detection by using error matrix prior to the construction of DT. These eleven VIs were NDVI, EVI2, EVI, GRVI, atmospherically resistant vegetation index (ARVI), green difference vegetation index (GDVI), green normalized difference vegetation index (GNDVI), difference vegetation index (DVI), normalized green (NG), ratio vegetation index (RVI) and enhanced normalized difference vegetation index (ENDVI). The four examined VIs showed higher than $65 \%$ overall accuracy, while the other VIs showed less than $50 \%$. Therefore, the four VIs, NDVI, EVI2, EVI, and GRVI were used for the further analysis.

The four examined vegetation indices were as follows:

$$
\begin{gathered}
\mathrm{NDVI}=(\mathrm{NIR}-\mathrm{red}) /(\mathrm{NIR}+\mathrm{red}) \\
\mathrm{GRVI}=(\text { green }- \text { red }) /(\text { green }+ \text { red })
\end{gathered}
$$


where near-infrared (NIR), red, green and blue represent (partially) atmospherically corrected surface reflectances, $\mathrm{L}$ denotes the canopy background adjustment used to address the nonlinear, differential transmittance of NIR and red wavelength radiances through a canopy, and $\mathrm{C}_{1}$ and $\mathrm{C}_{2}$ are the coefficients of the aerosol resistance term that uses the blue band to calibrate the aerosol influences in the red wavelength. The blue wavelength ranges from 445 $\mathrm{nm}$ to $516 \mathrm{~nm}$ on IKONOS and from $450 \mathrm{~nm}$ to $510 \mathrm{~nm}$ on WV2, the green wavelength ranges from $506 \mathrm{~nm}$ to $595 \mathrm{~nm}$ on IKONOS and from $510 \mathrm{~nm}$ to $580 \mathrm{~nm}$ on WV2, the red wavelength ranges from $632 \mathrm{~nm}$ to $698 \mathrm{~nm}$ on IKONOS and from $630 \mathrm{~nm}$ to $690 \mathrm{~nm}$ on WV2, and the NIR wavelength lies between $757 \mathrm{~nm}$ and $863 \mathrm{~nm}$ on IKONOS and between $765 \mathrm{~nm}$ and $901 \mathrm{~nm}$ on WV2. Therefore, the data collected by WV2 were comparable to the data acquired using the IKONOS sensor (Table 1).

Table 1 The four wavelength bands on IKONOS and WV2 images

\begin{tabular}{cccc}
\hline \multirow{2}{*}{ Band } & \multicolumn{2}{c}{ Wavelength (nm) } \\
\cline { 2 - 4 } Blue & $\min$ & 445 & IKONOS \\
& $\max$ & 516 & 510 \\
Green & $\min$ & 506 & 510 \\
& $\max$ & 595 & 580 \\
Red & $\min$ & 632 & 630 \\
& $\max$ & 698 & 690 \\
Near-infrared (NIR) & $\min$ & 757 & 765 \\
& $\max$ & 863 & 901 \\
\hline
\end{tabular}

The NDVI refers to two spectral bands of the photosynthetic output, i.e., the red and near-infrared bands (Huete et al. 1997). The NDVI ranges from -1 to +1 and increases with an increase in the vegetation greenness. However, the NDVI is skewed by background 
reflectances and atmospheric interference (Karnieli et al. 2013). In addition, the NDVI is

182

183 saturated in regions with a high biomass (Miura et al. 2001). To reduce these disadvantages of the NDVI, multiple VIs modified from the NDVI have been developed (Phompila et al. 2015).

The GRVI uses green and red bands to assess deforestation, forest degradation and canopy tree phenology (Motohka et al. 2010; Tucker 1979). The GRVI often focuses on seasonal fluctuations in the greenness by evaluating the colors of leaves at the canopy surface using the green band (Nagai et al. 2012).

The EVI was modified from the NDVI by adopting numerous coefficients within the EVI algorithm (Equation 3): $\mathrm{L}=1, \mathrm{C}_{1}=6, \mathrm{C}_{2}=7.5$, and gain factor $(\mathrm{G})=2.5$ (Rouse et al. 1974; Huete et al. 1994). These parameters are used to improve the sensitivity to high biomass regions and the vegetation monitoring capability of the EVI by dissociating the canopy background signal and diminishing atmospheric influences (Huete et al. 1999). Although the EVI2 measures the vegetation greenness without a blue band (Equation 4), it resembles the 3-band EVI when the data quality is high and atmospheric effects are insignificant (Jiang et al. 2008).

A DT classifier was applied to identify the land use types using the four examined VIs. The DT was implemented depending on multiple levels of decisions based on the properties of the input datasets (Mountrakis et al. 2011).

Accuracy assessment of the land use classification

Validating the land use classification is a prerequisite for confirming temporal land use changes (Foody 2002). Ground truth data of stratified land use classes at 182 locations marked with GPS were used for the validation (Figure 1). The ground truth points were selected by using a land use map (Anonymous 2013). These locations and their adjacent areas 
were recorded more than once to inspect the eight land use types. Based on the measurements, the land use types on the maps were repeatedly reclassified to minimize classification errors.

207 The accuracies of the land use classification schemes using the four VIs and of the

208 hierarchical classification using the DT classifier were tested using an error matrix analysis.

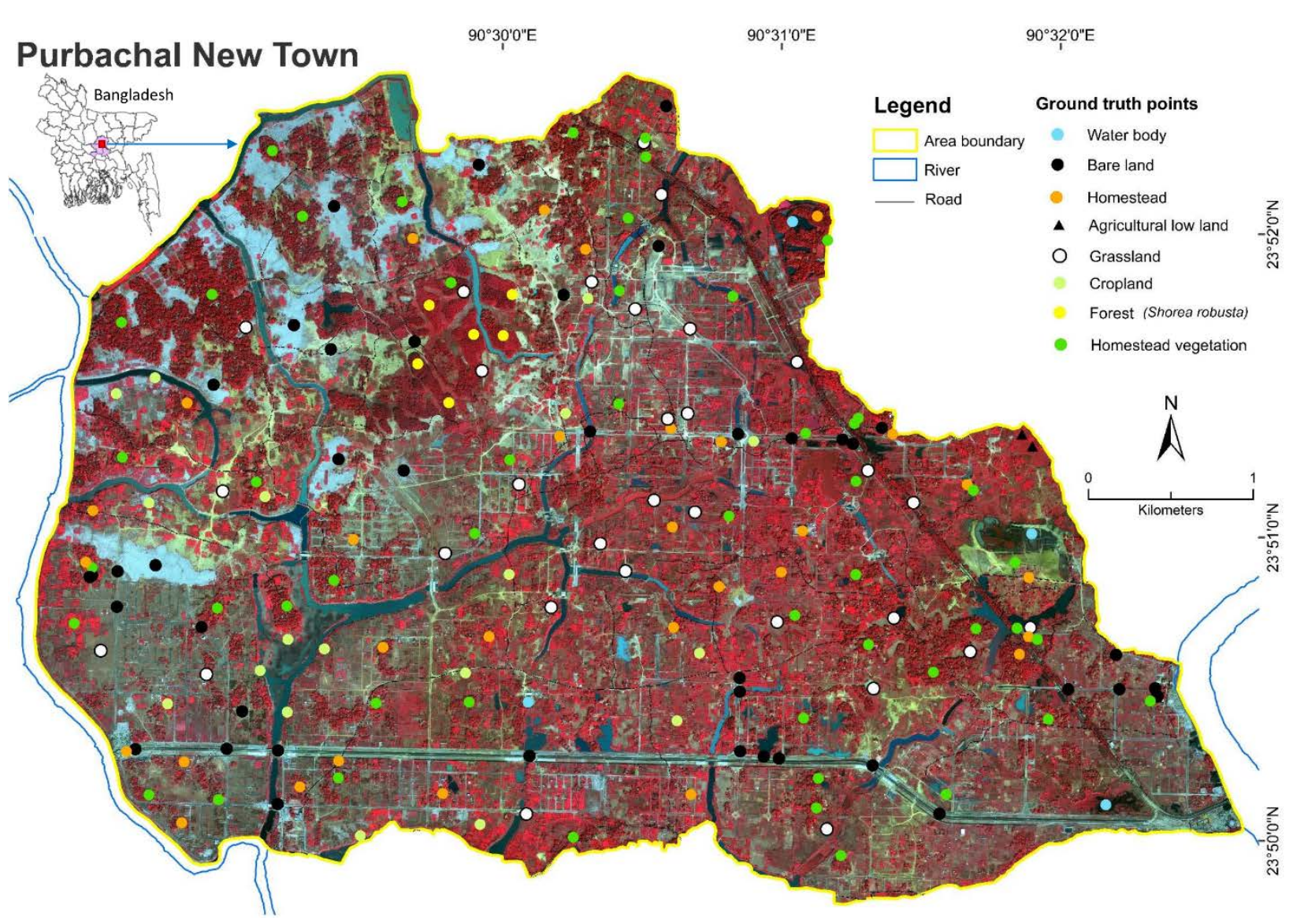

Fig. 1 Image of Purbachal New Town in 2015 from the WV2 satellite. Two rivers, namely, the Balu

214 and Sitalakhya Rivers, are distributed along the west and east sides of the township, respectively. The inset map at the top left shows Purbachal New Town in the country of Bangladesh. The 182 ground truth locations recorded via GPS in Purbachal New Town are shown on the WV2 natural color image using different colored circles for different land use types. The land use types were verified to assess the accuracy of the land use classification via satellite imagery and reference vegetation maps 
One-way analysis of variance (ANOVA) was used to investigate the significant differences in the VI values among the land use types. When the ANOVA was significant, Tukey post hoc multiple comparison tests were applied to determine the significant differences in the VIs among the land use types confirmed using ground truth data (Zar 1999).

\section{Results}

\section{Surface reflectances in the VIs}

226 The spatial patterns of the surface greenness in 2001 and 2015 were different among the VIs

227 (Figure 2). The GRVI effectively diagnosed the distributions of homestead vegetation and Shorea forest but often failed to discern cropland. The EVI detected the grassland distribution most correctly but could not clearly detect the Shorea forests. The NDVI differentiated water bodies and bare land but did not delineate the Shorea forest and homestead vegetation land use types, showing that the NDVI is not appropriate for classifying regions with dense green vegetation. The EVI2 distinguished vegetated land use types from non-vegetated land use types and clearly identified the homestead distribution.

The lowest NDVI value of -0.05 was obtained for water bodies due to the lack of vegetation (Figure 3). Homestead was detected within a few small patches with a low NDVI of 0.31 in 2001 and 0.21 in 2015, confirming that a fine-scale classification is required to detect these land use types. Homestead vegetation (i.e., vegetation enclosing homesteads) showed an NDVI of 0.91 in 2001 and 0.82 in 2015. Croplands had higher a NDVI than grassland of 0.67 in 2001 and 0.59 in 2015.

The lowest EVI values were shown for water bodies, while the second-lowest values 
242 clearly. The EVI of grassland was an average of 0.37, which is intermediate between the EVI

243 values for bare land and forests. EVI values between 0.37 and 0.48 were associated with

244 cropland and occasionally grassland, while EVI values ranging from 0.48 to 0.57 represented

245 dense and/or deeply green vegetation.
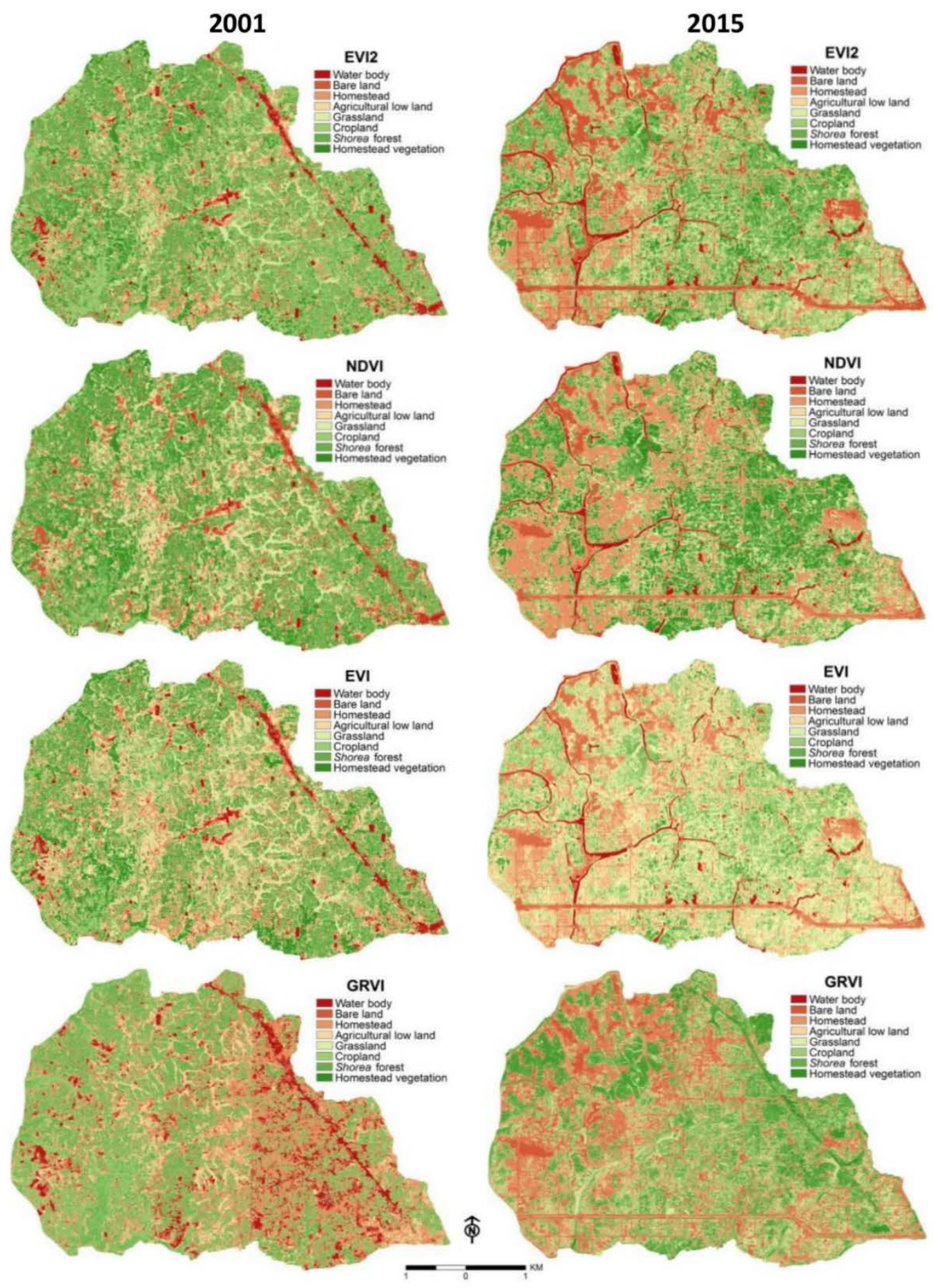
247 Fig. 2 Surface greenness distributions evaluated using the four VIs based on multi-temporal

248 information from the IKONOS and WV2 images in 2001 (left side) and 2015 (right side), respectively

249 The highest EVI2 value, i.e., 1, represented dense vegetation, including homestead vegetation.

250 The EVI2 value for Shorea forest was 0.97 , which was the highest of the examined VIs (0.77

251 with the NDVI, 0.53 with the EVI and 0.25 with the GRVI). The EVI2 value for grassland

252 ranged from 0.10 to 0.49 , which is higher than those obtained with the EVI, NDVI and GRVI.

253 The EVI2 sometimes misclassified cropland as grassland, probably because of double

254 cropping. An EVI2 value lower than 0.10 indicated poorly vegetated land use types, such as

255 bare land and sparse grassland. The GRVI demonstrated an appropriate detection of densely

256 vegetated land use types, mostly due to the discrimination of Shorea forest and homestead

257 vegetation. However, the GRVI did not effectively discriminate among water bodies, bare

258 land and homestead (Figure 2). Non-vegetated land, i.e., water bodies and bare land, showed

259 GRVI values of less than 0.18. Bare land and water bodies showed the lowest GRVI values

260 of -0.04 and 0.01 , respectively, while water bodies showed the lowest VI values overall.

261 These results indicate that the GRVI performed better while distinguishing dense vegetation

262 than other land use types characterized by sparse greenness.

263 In total, the NDVI had higher values than the EVI and GRVI, particularly when the

264 reflectance was high (Figure 3). The GRVI occasionally showed negative values over bare

265 land when it should have been higher than 0, which was probably due to soil interference. All

266 of the VIs showed a clear gap between non-vegetated and vegetated land use types. However,

267 in areas with a high vegetation, the VIs exhibited different responses to greenness. 


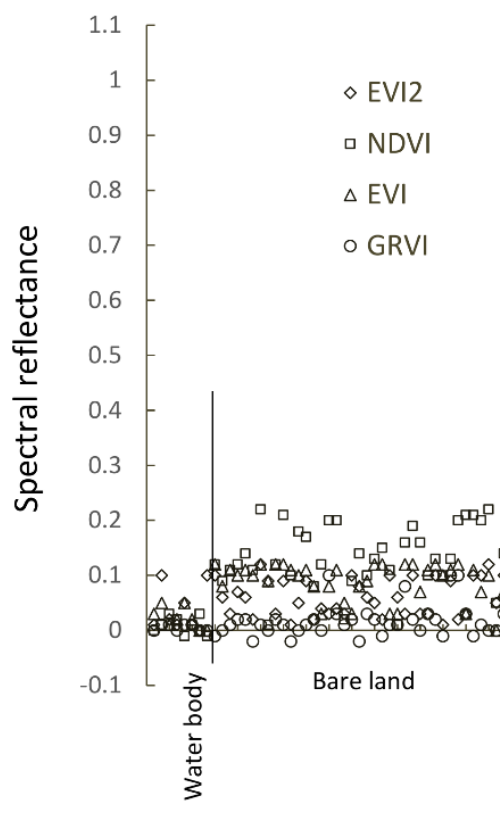

(a)

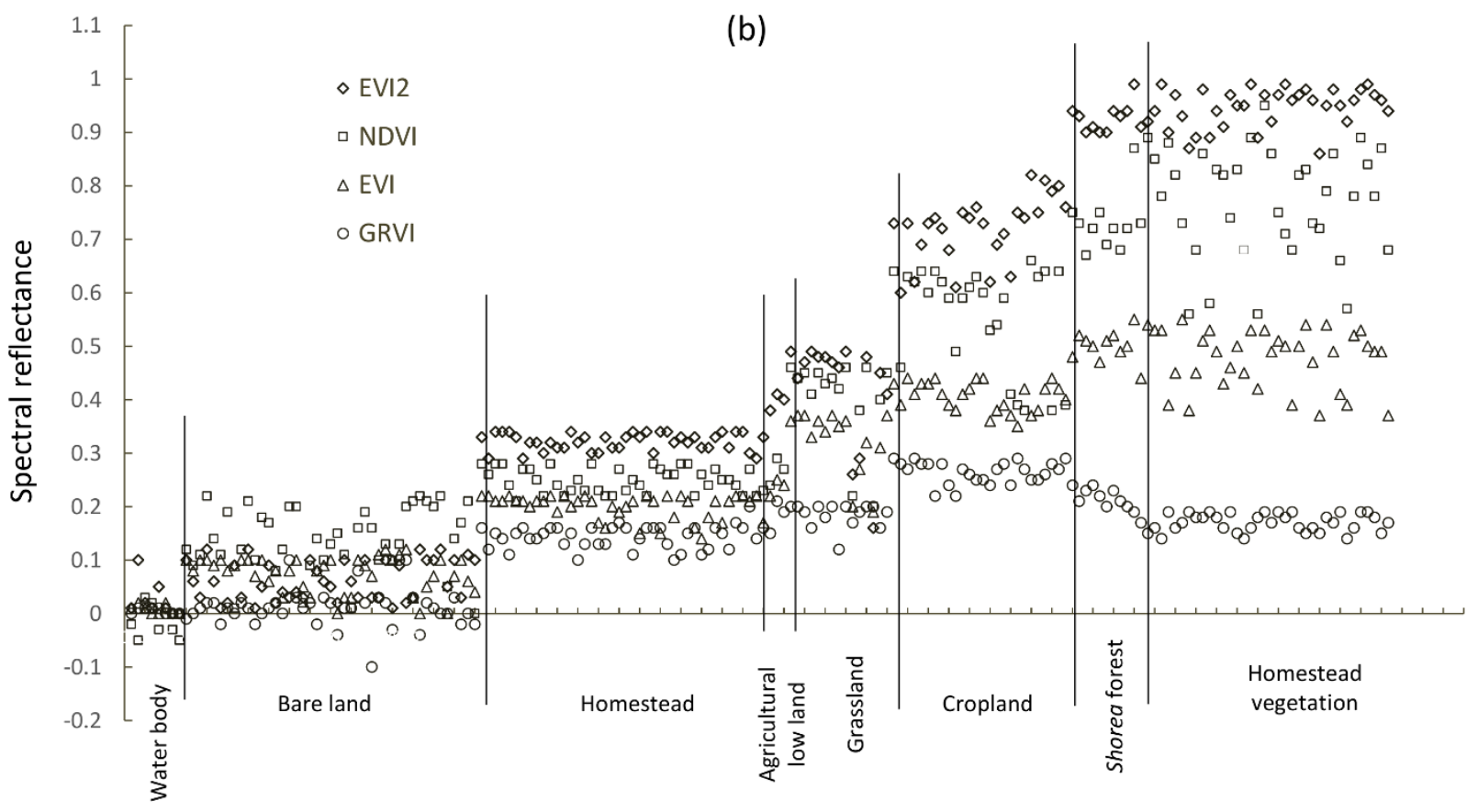

Land use types

269 Fig. 3 Spectral reflectances in the VIs extracted from 182 ground truth points for eight land use

270 classes. The y-axis indicates the spectral reflectances among the four VIs, while the x-axis represents

271 the eight land use types

272 Validation of the VIs

273 The accuracies of the land type classification schemes were different among the VIs (Table 3). 
274 Each of the four VIs showed different values among the land use types (ANOVA, $p<$

275 0.0001) (Table 2). All of the VIs showed stable values over homesteads. The EVI2 and NDVI

276 responses to grassland and cropland fluctuated, and the EVI fluctuated largely over Shorea

277 forest and homestead vegetation. Although the GRVI responses to Shorea forest and

278 homestead vegetation were stable, the GRVI responses were lower than the responses of the

279 other VIs.

The EVI2 exhibited different pairs of land use types except for grassland-agricultural

281 low land, agricultural low land-homestead and bare land-water body (Tukey test, $p<0.05$ ).

The NDVI exhibited different pairs of land use types except for homestead vegetation-Shorea forest, agricultural low land-homestead and grassland-agricultural low land. The homestead vegetation-Shorea forest and agricultural low land-homestead pairs were not significantly different in the EVI, although the rest of the pairs were different. The GRVI was capable of distinguishing between homestead vegetation and Shorea forest, but the other three VIs could not differentiate these two land use types. The GRVI did not reveal significant differences in the comparisons between the other land use types $(p<0.05)$. The GRVI was most effective at differentiating the Shorea forest-homestead vegetation pair; meanwhile, the EVI2 and NDVI effectively detected homestead, bare land and water bodies, and the EVI effectively detected the distributions of agricultural low land, grassland and cropland. 
Table 2 Mean and standard error (SE) of each VI for the eight land use types. All of the VIs obtained in 2001 and 2015 among the land use types are significantly different (one-way ANOVA, $p<0.0001$ ). Identical letters indicate that the VIs are not significantly different between those land

294 use types (Tukey test, $p<0.05$ )

295

\begin{tabular}{|c|c|c|c|c|c|c|c|c|c|}
\hline & & Water body & Bare land & Homestead & $\begin{array}{l}\text { Agricultural low } \\
\text { land }\end{array}$ & Grassland & Cropland & $\begin{array}{c}\text { Forest } \\
\text { (Shorea } \\
\text { robusta) }\end{array}$ & $\begin{array}{l}\text { Homestead } \\
\text { vegetation }\end{array}$ \\
\hline \multirow{4}{*}{ ¿্ర } & $\sum^{2}$ & $\begin{array}{c}0.04 \pm 0.02 \\
a\end{array}$ & $\begin{array}{c}0.06 \pm 0.01 \\
a\end{array}$ & $\begin{array}{c}0.32 \pm 0.00 \\
b\end{array}$ & $\begin{array}{c}0.42 \pm 0.01 \\
c\end{array}$ & $\begin{array}{c}0.42 \pm 0.03 \\
c\end{array}$ & $\begin{array}{c}0.74 \pm 0.01 \\
d\end{array}$ & $\begin{array}{c}0.96 \pm 0.00 \\
\mathrm{e}\end{array}$ & $\begin{array}{c}0.96 \pm 0.01 \\
e\end{array}$ \\
\hline & 之o & $\begin{array}{c}0.01 \pm 0.01 \\
a\end{array}$ & $\begin{array}{c}0.14 \pm 0.01 \\
b\end{array}$ & $\begin{array}{c}0.30 \pm 0.00 \\
c\end{array}$ & $\begin{array}{c}0.31 \pm 0.01 \\
\mathrm{~cd}\end{array}$ & $\begin{array}{c}0.42 \pm 0.02 \\
d\end{array}$ & $\begin{array}{c}0.62 \pm 0.01 \\
\mathrm{e}\end{array}$ & $\begin{array}{c}0.73 \pm 0.01 \\
f\end{array}$ & $\begin{array}{c}0.79 \pm 0.02 \\
f\end{array}$ \\
\hline & 空 & $\begin{array}{c}0.02 \pm 0.01 \\
a\end{array}$ & $\begin{array}{c}0.09 \pm 0.01 \\
b\end{array}$ & $\begin{array}{c}0.22 \pm 0.00 \\
c\end{array}$ & $\begin{array}{c}0.26 \pm 0.01 \\
c\end{array}$ & $\begin{array}{c}0.34 \pm 0.01 \\
d\end{array}$ & $\begin{array}{c}0.43 \pm 0.01 \\
e\end{array}$ & $\begin{array}{c}0.51 \pm 0.01 \\
f\end{array}$ & $\begin{array}{c}0.51 \pm 0.01 \\
f\end{array}$ \\
\hline & $\underset{\mathbb{1}}{>}$ & $\begin{array}{c}0.01 \pm 0.00 \\
a\end{array}$ & $\begin{array}{c}0.01 \pm 0.01 \\
a\end{array}$ & $\begin{array}{c}0.17 \pm 0.00 \\
b\end{array}$ & $\begin{array}{c}0.27 \pm 0.01 \\
\text { cef }\end{array}$ & $\begin{array}{c}0.21 \pm 0.00 \\
\mathrm{dfg}\end{array}$ & $\begin{array}{c}0.27 \pm 0.01 \\
\mathrm{e}\end{array}$ & $\begin{array}{c}0.23 \pm 0.01 \\
f\end{array}$ & $\begin{array}{c}0.19 \pm 0.00 \\
g\end{array}$ \\
\hline \multirow{4}{*}{$\stackrel{n}{\circ}$} & $\sum^{2}$ & $\begin{array}{c}0.03 \pm 0.01 \\
a\end{array}$ & $\begin{array}{c}0.06 \pm 0.01 \\
a\end{array}$ & $\begin{array}{c}0.32 \pm 0.00 \\
b\end{array}$ & $\begin{array}{c}0.40 \pm 0.01 \\
\text { bc }\end{array}$ & $\begin{array}{c}0.42 \pm 0.03 \\
c\end{array}$ & $\begin{array}{c}0.72 \pm 0.01 \\
d\end{array}$ & $\begin{array}{c}0.92 \pm 0.01 \\
\mathrm{e}\end{array}$ & $\begin{array}{c}0.95 \pm 0.01 \\
\mathrm{e}\end{array}$ \\
\hline & 2 & $\begin{array}{c}-0.02 \pm 0.01 \\
a\end{array}$ & $\begin{array}{c}0.14 \pm 0.01 \\
b\end{array}$ & $\begin{array}{c}0.25 \pm 0.00 \\
c\end{array}$ & $\begin{array}{c}0.27 \pm 0.02 \\
\mathrm{~cd}\end{array}$ & $\begin{array}{c}0.41 \pm 0.02 \\
d\end{array}$ & $\begin{array}{c}0.56 \pm 0.02 \\
\mathrm{e}\end{array}$ & $\begin{array}{c}0.71 \pm 0.01 \\
f\end{array}$ & $\begin{array}{c}0.77 \pm 0.02 \\
f\end{array}$ \\
\hline & 茨 & $\begin{array}{c}0.01 \pm 0.00 \\
a\end{array}$ & $\begin{array}{c}0.08 \pm 0.01 \\
b\end{array}$ & $\begin{array}{c}0.2 \pm 0.00 \\
c\end{array}$ & $\begin{array}{c}0.24 \pm 0.01 \\
c\end{array}$ & $\begin{array}{c}0.33 \pm 0.02 \\
d\end{array}$ & $\begin{array}{c}0.41 \pm 0.01 \\
\mathrm{e}\end{array}$ & $\begin{array}{c}0.50 \pm 0.01 \\
f\end{array}$ & $\begin{array}{c}0.48 \pm 0.01 \\
f\end{array}$ \\
\hline & 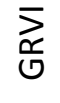 & $\begin{array}{c}0.01 \pm 0.00 \\
a\end{array}$ & $\begin{array}{c}0.01 \pm 0.01 \\
a\end{array}$ & $\begin{array}{c}0.14 \pm 0.00 \\
b\end{array}$ & $\begin{array}{c}0.18 \pm 0.02 \\
\text { bcdf }\end{array}$ & $\begin{array}{c}0.18 \pm 0.01 \\
\text { ce }\end{array}$ & $\begin{array}{c}0.26 \pm 0.00 \\
f\end{array}$ & $\begin{array}{c}0.22 \pm 0.01 \\
d\end{array}$ & $\begin{array}{c}0.17 \pm 0.00 \\
\mathrm{e}\end{array}$ \\
\hline
\end{tabular}


297 A hierarchical land use classification was developed using a DT classifier with the four VIs 298 (Figure 4).

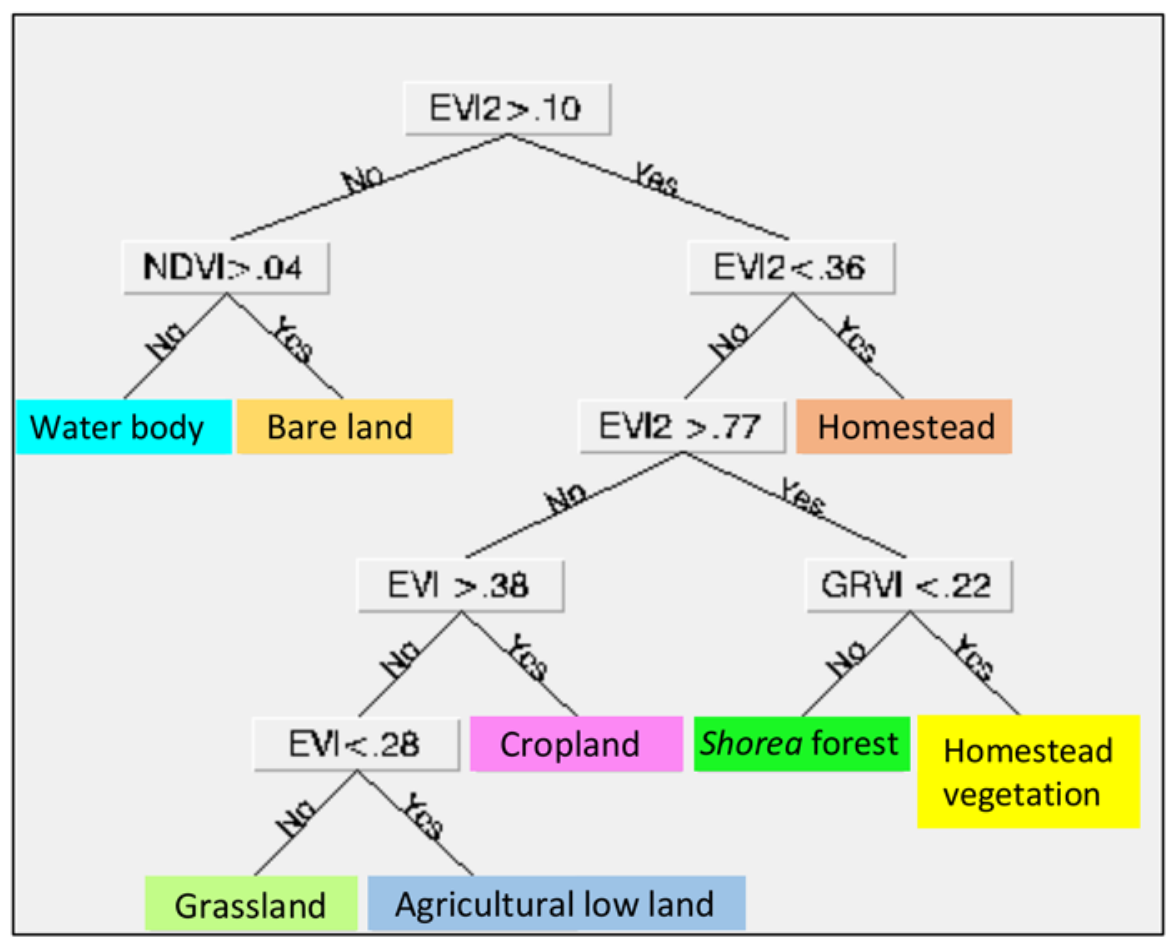

300 Fig. 4 A DT constructed using the hierarchical classification of land use types. Numerals with inequality signs indicate the VI values that represent the thresholds of the classifiers

302 The DT begins with the EVI2, which then separates the land use types into vegetated and non303 vegetated land use types. The NDVI then separates the non-vegetated land uses into water bodies 304 and bare land. Meanwhile, among the vegetated land use types, the EVI2 extracts the homestead 305 distribution and the EVI detects agricultural low land, grassland and cropland. Among the four 306 VIs, homestead vegetation and Shorea forest were separated only through the GRVI. 

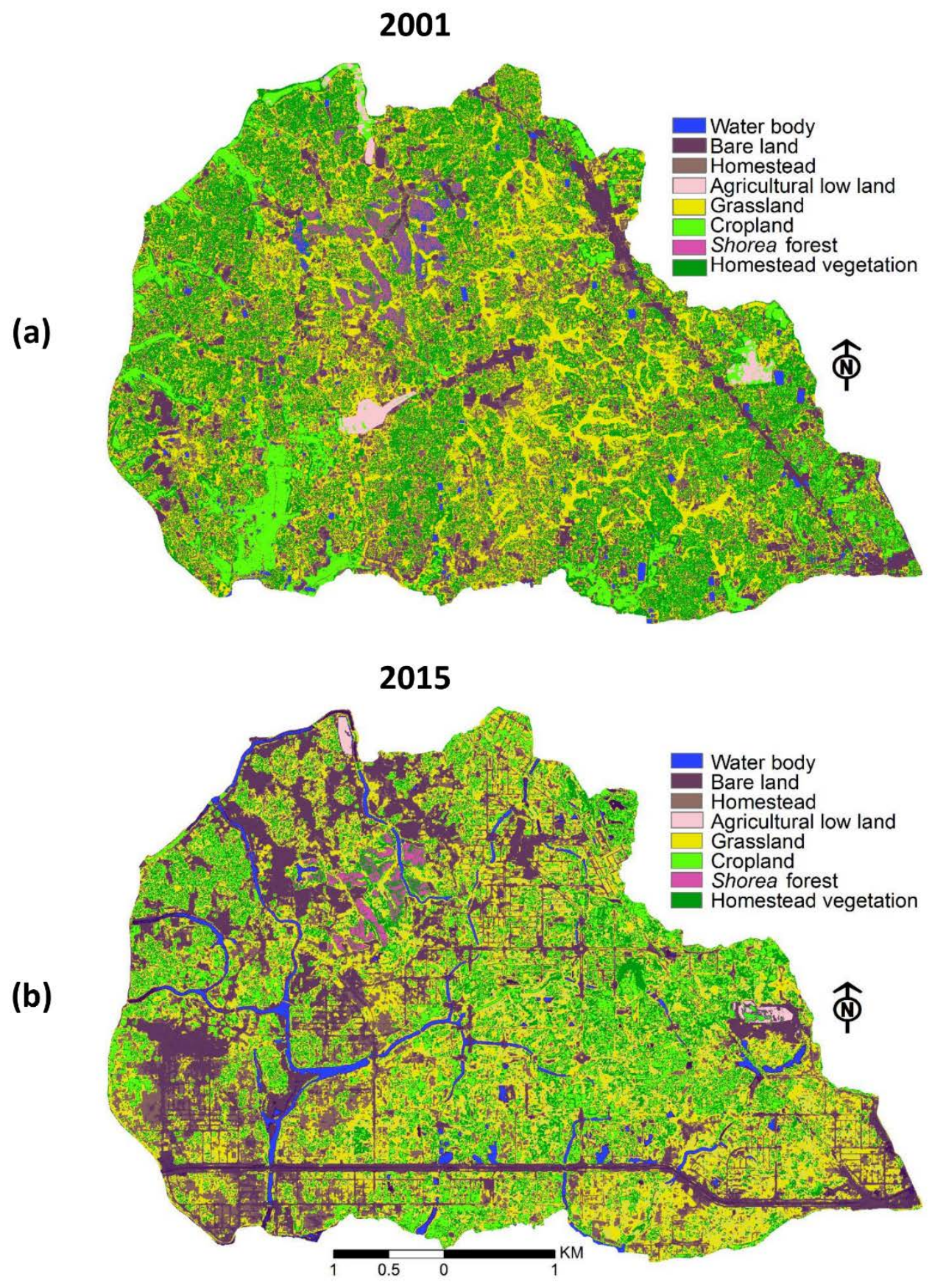

308 Fig. 5 Land use maps produced through a hierarchical classification using the DT approach. These maps

309 show the temporal changes in the land use-land cover throughout Purbachal New Town from 2001 to

310 2015. a) Land use patterns detected using the IKONOS sensor in 2001. The land use patterns were

311 verified using a pre-project land use map (Anonymous 2013). b) Land use patterns in 2015 were detected

312 using WV2 multi-spectral imagery. The land use types are represented by their respective colors 
Table 3 Classification accuracies examined using an error matrix of $\kappa$ coefficients

\begin{tabular}{ccccc}
\hline & \multicolumn{2}{c}{2001} & \multicolumn{2}{c}{2015} \\
\hline Classification & $\begin{array}{c}\text { Overall } \\
\text { accuracy (\%) }\end{array}$ & $\begin{array}{c}\kappa \\
\text { coefficient }\end{array}$ & $\begin{array}{c}\text { Overall accuracy } \\
(\%)\end{array}$ & $\begin{array}{c}\kappa \\
\text { coefficient }\end{array}$ \\
\hline EVI2 & 90.1 & 0.88 & 91.2 & 0.89 \\
NDVI & 88.5 & 0.86 & 89.6 & 0.87 \\
EVI & 66.5 & 0.60 & 67.6 & 0.61 \\
GRVI & 74.2 & 0.69 & 77.5 & 0.73 \\
DT & 96.1 & 0.95 & 97.8 & 0.97 \\
\hline
\end{tabular}

The DT approach showed the highest accuracy (with an accuracy greater than 95\% and a

$315 \kappa$ of greater than 0.95 , see Table 3 ) during the land use classification, indicating that the DT

316 constructed using the four VIs was the most effective at predicting the land use types (Figure 5).

317 The second-highest accuracy and $\kappa$ values ( $91.2 \%$ and 0.89 , respectively) were exhibited by the

318 EVI2 measurements from 2015, indicating that the DT effectively improved the land use

319 classification scheme.

\section{$320 \quad$ LULC changes}

321 Based on the land use changes from 2001 to 2015 (Figure 5), the characteristics of the land use

322 changes were examined (Table 4). Road networks and their adjacent areas were clearly observed.

323 Homestead vegetation, grassland, cropland and homestead were the dominant land use types

324 prior to urbanization, but more than three-quarters of the area of each land use type was lost

325 thereafter. Approximately one-half of the area of Shorea forest was lost subsequent to

326 urbanization. Since the distribution of bare land increased greatly, the reduction in the area of

327 each land use type can be derived according to an increase in bare land originating from road

328 construction and other related construction projects, and the water body area was also increased

329 due to the excavation of artificial lakes and canals. Grasses colonized in the filed up agricultural

330 low land and consequently, the grassland increased. Since most of the water bodies were small 
331 and/or narrow, those changes were detectable only at a high resolution.

332

Table 4 Changes in the eight land use types from 2001 to 2015 based on satellite imagery

\begin{tabular}{lcccc}
\hline \multicolumn{1}{c}{ Land use types } & $\begin{array}{c}2001 \\
\text { Area }\left(\mathrm{km}^{2}\right)\end{array}$ & $(\%)$ & $\begin{array}{c}2015 \\
\text { Area }\left(\mathrm{km}^{2}\right)\end{array}$ & $(\%)$ \\
\hline Water body & 0.59 & 2.37 & 2.12 & 8.52 \\
Bare land & 0.14 & 0.56 & 16.97 & 68.17 \\
Homestead & 3.02 & 12.13 & 0.86 & 3.46 \\
Agricultural low land & 0.67 & 2.69 & 0.04 & 0.16 \\
Grassland & 1.03 & 4.14 & 1.06 & 4.26 \\
Cropland & 6.26 & 25.15 & 0.59 & 2.37 \\
Forest (Shorea robusta) & 0.77 & 3.09 & 0.42 & 1.69 \\
Homestead vegetation & 12.41 & 49.86 & 2.83 & 11.37 \\
\hline
\end{tabular}

\section{Discussion}

334 Effectiveness of the VIs and the DT approach

335 A comparison among the DT and VIs indicates that all four of the examined VIs showed specific 336 advantages and disadvantages with regard to the land use classification at a fine resolution. The 337 reflectances of the blue and green wavelengths can characterize the spatiotemporal fluctuation 338 patterns of VIs (Huete 1988). The EVI2 differentiated between vegetated and non-vegetated land 339 use types without using the blue band. Only the GRVI classified dense vegetation, i.e.,

340 homestead vegetation and Shorea forests, probably because the GRVI is sensitive to the canopy

341 surfaces of forests (Nagai et al. 2012). Therefore, the GRVI constituted a prerequisite for the

342 classification of deeply green areas, i.e., forests, although the overall accuracy of the associated 343 classification was low. 
The EVI2 showed the highest accuracy among the examined VIs at a fine resolution

345 (Kushida et al. 2015). However, the EVI2 did not effectively differentiate between homestead

346 vegetation and Shorea forest. The EVI2 maintains a high sensitivity and linearity to high

347 phytomass densities (Rocha and Shaver 2009). However, there are many difficulties when using

348 the EVI2 to conduct a land use classification in tropical/sub-tropical regions such as Bangladesh,

349 because persistent evergreen forests show high reflectances both in and out of season (Cristiano

350 et al. 2014). The accuracy of the NDVI land classification was slightly lower than that of the

351 EVI2 results. The NDVI is skewed by the background reflectance, including those of bright soils

352 and non-photosynthetic plant organs (i.e., trash and tree trunks) (Van Leeuwen and Huete 1996).

353 Because the examined data did not contain a substantial amount of clouds, the EVI2 and NDVI

354 seemed to synchronize their fluctuations.

The EVI effectively classified the grassland, cropland and agricultural low land types, but

356 it did not distinguish the other land use types, suggesting that the blue band used only by the EVI

357 influenced the resulting land use classification. However, the EVI is distorted by the soil

358 adjustment factor L in Equation (3), making it more sensitive to topographic conditions

359 (Wardlow et al. 2007). Therefore, the EVI did not seem to function well.

The DT using the four VIs largely improved the accuracy of the land use classification.

361 The accuracy of the DT was slightly different between the two surveyed years (96.1\% in 2001

362 and $97.8 \%$ in 2015, see Table 3). One cause of this difference was probably derived from

363 differences in the quality of the data, i.e., with regard to the resolution, photographing conditions

364 and sensors, from IKONOS in 2001 and from WV2 in 2015.

365 Temporal land use changes caused by urbanization

366 This research used highly resolved, multi-temporal satellite data to develop a methodology for 
367 assessing land use changes. The results of the VIs vary between fine and coarse resolution. The

368 fine-scale land use classification scheme clearly detected fine-scale land use patches generated

369 by the development of road networks subsequent to urbanization that cannot be detected during

370 coarse-scale analysis. Accordingly, land use classification schemes are often dependent upon the

371 resolution (O’Connell et al. 2013). Since roadways are a few tens of meters wide, high-resolution

372 data are required for the classification of urban landscapes. Fine-scale data can delineate land

373 cover classes more accurately, because such data can identify small and/or linear patches while

374 retaining their shapes (Boyle et al. 2014). Ongoing urbanization has been followed by drastic

375 changes in the land use types, biodiversity and fragile ecosystems of urbanized areas (Merlotto et

376 al. 2012; Zhou and Zhao 2013; Pigeon et al. 2006). The urbanization of Purbachal New Town

377 was characterized by a substantial loss of homestead vegetation and cultivable land. Furthermore,

378 approximately one-half of native Shorea forests were lost, even though the master plan of

379 urbanization considered their conservation (Hasnat and Hoque 2016). Land use changes

380 associated with deforestation have not been detected well. The endangered Shorea forests are

381 likely to be restored and conserved through the identification of small and isolated patches using

382 the fine-scale analysis. The species distribution modeling should be executed for the restoration

383 of the threatened ecosystems using the identified distinct small patches. Also, land

384 transformation model would be implemented using fine-scale data to show the process of land

385 use changes (Pijanowski et al. 2002). These approaches are the pronounced concern for the

386 planners to protect and preserve the endangered ecosystems from being extinction.

Imagery acquired by two or more satellites is often used to examine temporal land use

388 changes depending on the data availability. This study used two sets of satellite imagery, namely,

389 from the IKONOS and WV2 sensors. Using multiple sensors can often cause errors in the land 
use classification due to heterogeneities in the spatial resolution of the data (Joshi et al. 2016; Xie et al. 2008). However, integrating the IKONOS and WV2 data resulted in a smaller error and higher accuracy; this was probably because of the finer resolutions and greater overlap of the wavelength bands. Fine-resolution data may partly resolve such errors by reducing the mismatches in the overlays of wavelength bands.

\section{Conclusion}

A DT constructed using a hierarchical classification greatly improved the classification of land use types at a fine resolution. The DT was developed using all of the four examined VIs because each VI demonstrated unique strengths and limitations. For example, the GRVI showed the lowest overall accuracy, but it was retained in the DT because the GRVI can effectively classify areas with a high greenness. The land use classification scheme using the DT clarified that the changes in Purbachal New Town are characterized by the effects of road networks on deeply green ecosystems, which are unlikely to be detected clearly at coarse resolutions. Therefore, this research showed a significant monitoring source to investigate the continuous changes in land use types and assist the planners and decision makers to develop land use management plans.

\section{References}

Aguilar, M. A., Saldaña, M. M., \& Aguilar, F. J. (2013). GeoEye-1 and WorldView-2 pansharpened imagery for object-based classification in urban environments. International Journal of Remote Sensing, 34, 2583-2606. https://doi.org/10.1080/01431161.2012.747018.

Anonymous (2013). Environmental Impact Assessment (EIA) of Purbachal New Town Project. Rajdhani Unnayan Kartripakkha (RAJUK), Ministry of Housing and Public Works, Government of the People's Republic of Bangladesh. 
Akay, S. S., \& Sertel, E. (2016). Urban land cover/use change detection using high resolution spot 5 and spot 6 images and urban atlas nomenclature. The International Archives of the Photogrammetry, Remote Sensing and Spatial Information Sciences, XLI-B8, 789-796. XXIII ISPRS Congress, Prague, Czech Republic. https://doi.org/10.5194/isprs-archives$\underline{\text { XLI-B8-789-2016. }}$

Barzegar, M., Ebadi, H., \& Kiani, A. (2015). Comparison of different vegetation indices for very high-resolution images, specific case UltraCam-D imagery. Remote Sensing and Spatial Information Sciences, XL-1/W5. https://doi.org/10.5194/isprsarchives-XL-1-W5-97-2015.

Brown De Colstoun, E. C. B., Story, M. H., Thompson, C., Commisso, K., Smith, T. G., \& Irons, J. R. (2003). National Park vegetation mapping using multi-temporal Landsat 7 data and a decision tree classifier. Remote Sensing of Environment, 85, 316-327.

Boyle, S. A., Kennedy, C. M., Torres, J., Colman, K., Pérez-Estigarribia, P. E., \& de la Sancha, N. U. (2014). High-Resolution Satellite Imagery Is an Important yet Underutilized Resource in Conservation Biology. PLoS ONE, 9, e86908. http://doi.org/10.1371/journal.pone.0086908.

Cristiano, P. M., Madanes, N., Campanello, P. I., di Francescantonio, D., Rodríguez, S. A., Zhang, Y-J., Carrasco, L. O., \& Goldstein, G. (2014). High NDVI and potential canopy photosynthesis of south American subtropical forests despite seasonal changes in leaf area index and air temperature. Forests, 5, 287-308. doi:10.3390/f5020287.

Dewan, A. M., \& Yamaguchi, Y. (2009). Using remote sensing and GIS to detect and monitor land use and land cover change in Dhaka Metropolitan of Bangladesh during 1960-2005. Environ Monit Assess, 150, 237-249. doi: 10.1007/s10661-008-0226-5.

Dibs, H., Idrees, M. O., \& Alsalhin, G. B. A. (2017). Hierarchical classification approach for mapping rubber tree growth using per-pixel and object-oriented classifiers with SPOT-5 imagery. The Egyptian Journal of Remote Sensing and Space Sciences, 20, 21-30. http://dx.doi.org/10.1016/j.ejrs.2017.01.004.

Erener, A., Düzgün, S., \& Yalciner, A. C. (2012). Evaluating land use/cover change with temporal satellite data and information systems. Procedia Technology, 1, 385-389. https://doi.org/10.1016/j.protcy.2012.02.079.

Fisher, J. R. B., Acosta, E. A., Dennedy-Frank, P. J., Kroeger, T., \& Boucher, T. M. (2017). Impact of satellite imagery spatial resolution on land use classification accuracy and 
modeled water quality. Remote Sensing in Ecology and Conservation, 1-13. https://doi.org/10.1002/rse2.61.

Fonji, S. F., \& Taff, G. N. (2014). Using satellite data to monitor land-use land-cover change in North-eastern Latvia. Springer Plus, 3(61). https://doi.org/10.1186/2193-1801-3-61.

Foody, G. M. (2002). Status of land cover classification accuracy assessment. Remote Sensing of Environment, 80, 185-201. https://doi.org/10.1016/S0034-4257(01)00295-4.

Gautam, K. H., \& Devoe, N. N. (2006). Ecological and anthropogenic niches of sal (Shorea robusta Gaertn. f.) forest and prospects for multiple-product forest management - a review. Forestry (Lond), 79, 81-101. https://doi.org/10.1093/forestry/cpi063.

Hasnat, M. M., \& Hoque, M. S. (2016). Developing Satellite Towns: A Solution to Housing Problem or Creation of New Problems. IACSIT International Journal of Engineering and Technology, 8, 50-56.

Hassan, M. M. (2004). A study on flora species diversity and their relations with farmers' socioagro-economic condition in Madhupur Sal forest. Dissertation, Department of Agroforestry, Bangladesh Agricultural University, Mymensingh, Bangladesh.

Holben, B. N., \& Justice, C. O. (1981). An examination of spectral band ratioing to reduce the topographic effect on remotely sensed data. International Journal of Remote Sensing, 2, 115-133. http://dx.doi.org/10.1080/01431168108948349.

Hossain, S. (2013). Migration, urbanization and poverty in Dhaka, Bangladesh. Journal of the Asiatic Society of Bangladesh (Hum.), 58, 369-382.

Huete, A. (1988). A soil-adjusted vegetation index (SAVI). Remote Sensing of Environment, 25, 295-309.

Huete, A. R., Justice, C., \& van Leeuwen, W. (1999). MODIS Vegetation Index (MOD13) Algorithm Theoretical Basis Document. Version 3.1. Vegetation Index and Phenology Lab, The University of Arizona.

Huete, A. R., Liu, H. Q., Batchily, K., \& van Leeuwen, W. (1997). A Comparison of Vegetation Indices over a Global set of TM Images for EOS-MODIS. Remote Sensing of Environment, 59, 440-451. doi:10.1016/S0034-4257(96)00112-5.

Huete, A., Justice, C., \& Liu, H. (1994). Development of vegetation and soil indices for MODISEOS. Remote Sensing of Environment, 49, 224-234. 
Huete, A., Didan, K., Miura, T., Rodriguez, E. P., Gao, X., \& Ferreira, L. G. (2002). Overview of the Radiometric and Biophysical Performance of the MODIS Vegetation Indices. Remote Sensing of Environment, 83, 195-213. doi: 10.1016/S0034-4257(02)00096-2. Jiang, Z., Huete, A. R., Didan, K., \& Miura, T. (2008). Development of a two-band enhanced vegetation index without a blue band. Remote Sensing of Environment, 112, 3833-3845.

Jiang, Z., Huete, A. R., Kim, Y., \& Didan, K. (2007). 2-band enhanced vegetation index without a blue band and its application to AVHRR data. Remote Sensing and Modeling of Ecosystems for Sustainability, 6679 667905, 1-9. http://dx.doi.org/10.1117/12.734933.

Joshi, Chandra, P. (2011). Performance evaluation of vegetation indices using remotely sensed data. International journal of geomatics and geosciences, 2, 231-240. ISSN 0976 - 4380.

Joshi, N., Baumann, M., Ehammer, A., Fensholt, R., Grogan, K., Hostert, P., Jepsen, M. R. et al. (2016). A Review of the Application of Optical and Radar Remote Sensing Data Fusion to Land Use Mapping and Monitoring. Remote Sens, 8, 70. doi:10.3390/rs8010070.

Julien, Y., Sobrino, J. A., Mattar, C., Ruescas, A. B., Jime’nez-Munoz, J. C., So`ria, G., Hidalgo, V., Atitar, M., Franch, B., \& Cuenca, J. (2011). Temporal analysis of normalized difference vegetation index (NDVI) and land surface temperature (LST) parameters to detect changes in the Iberian land cover between 1981 and 2001. International Journal of Remote Sensing, 32, 2057-2068. https://doi.org/10.1080/01431161003762363.

Kalyani, P., \& Govindarajulu, P. (2015). Multi-Scale Urban Analysis Using Remote Sensing and GIS. Geoinformatica: An International Journal (GIIJ), 5, 1-11.

Karnieli, A., Bayarjargal, Y., Bayasgalan, M., Mandakh, B., Dugarjav, C., Burgheimer, J., Khudulmur, S., Bazha, S. N., \& Gunin, P. D. (2013). Do vegetation indices provide a reliable indication of vegetation degradation? A case study in the Mongolian pastures. International Journal of Remote Sensing, 34, 6243-6262. https://doi.org/10.1080/01431161.2013.793865.

Khatun, H., Falgunee, N., \& Kutub, M. J. R. (2015). Analyzing urban population density gradient of Dhaka Metropolitan Area using Geographic Information Systems (GIS) and Census Data. Malaysian Journal of Society and Space, 13, 1-13. ISSN 2180-2491. 
Kinthada N. R., Gurram, M. K., Eadara, A., \& Velagala, V. R. (2014). Land Use/Land Cover and NDVI Analysis for Monitoring the Health of Micro-watersheds of Sarada River Basin, Visakhapatnam District, India. J Geol Geosci, 3, 146. doi:10.4172/2329-6755.1000146.

Kushida, K., Hobara, S., Tsuyuzaki, S., Kim, Y., Watanabe, M., Setiawan, Y., Harada, K., Shaver, G. R., \& Fukuda, M. (2015). Spectral indices for remote sensing of phytomass, deciduous shrubs, and productivity in Alaskan Arctic tundra. International Journal of Remote Sensing, 36, 4344-4362. https://doi.org/10.1080/01431161.2015.1080878.

Laliberte, A. S., Fredrickson, E. L., \& Rango, A. (2007). Combining decision trees with hierarchical object-oriented image analysis for mapping arid rangelands. Journal of Photogrammetric Engineering and Remote Sensing, 73, 197-207.

Lunetta, R. S., Knight, J. F., Ediriwickrema, J., Lyon, J. G., \& Worthy, L. D. (2006). Land-cover change detection using multi-temporal MODIS NDVI data. Remote Sensing of Environment, 105, 142-154.

Mandal, R. A., Yadav, B. K. V., Yadav, K. K., Dutta, I. C., \& Haque, S. M. (2013). Biodiversity comparison of natural Shorea robusta mixed forest with Eucalyptus Camaldulensis plantation in Nepal. Scholars Academic Journal of Biosciences (SAJB), 1, 144-149.

Markogianni, V., Dimitriou, E., \& Kalivas, D. P. (2013). Land-use and vegetation change detection in Plastira artificial lake catchment (Greece) by using remote sensing and GIS techniques. International Journal of Remote Sensing, 34, 1265-1281. https://doi.org/10.1080/01431161.2012.718454.

Matsushita, B., Yang, W., Chen, J., Onda, Y., \& Qiu, G. (2007). Sensitivity of the Enhanced Vegetation Index (EVI) and Normalized Difference Vegetation Index (NDVI) to Topographic Effects: A Case Study in High-Density Cypress Forest. Sensors, 7, 26362651.

Merlotto, A., Piccolo, M. C., \& Bertola, G. R. (2012). Urban growth and land use/cover change at Necochea and Quequen cities, Buenos Aires province, Argentina. Revista de Geografia Norte Grande, 53, 159-176.

Miura, T., Huete, A. R., Yoshioka, H., \& Holben, B. N. (2001). An error and sensitivity analysis of atmospheric resistant vegetation indices de-rived from dark target-based atmospheric correction. Remote Sensing of Environment, 78, 284-298. 
Motohka, T., Nasahara, K. N., Oguma, H., \& Tsuchida, S. (2010). Applicability of green-red Vegetation Index for remote sensing of vegetation phenology. Remote Sensing, 2, 23692387. doi:10.3390/rs2102369.

Mountrakis, G., Im, J., \& Ogole, C. (2011). Support vector machines in remote sensing: a review. ISPRS J. Photogramm. Remote Sens., 66 (3), 247-259.

Myneni, R. B., Keeling, C. D., Tucker, C. J., Asrar, G., \& Nemani, R. R. (1997). Increased plant growth in the northern high latitudes from 1981 to 1991. Nature, 386, 698-702. doi:10.1038/386698a0.

Nagai, S., Saitoh, T. M., Kobayashi, H., Ishihara, M., Suzuki, R., Motohka, T., Nasahara, K. N., \& Muraoka, H. (2012). In situ examination of the relationship between various Vegetation Indices and canopy phenology in an evergreen coniferous forest, Japan. International Journal of Remote Sensing, 33, 6202-6214.

Nigam, R. K. (2000). Application of Remote Sensing and Geographical Information System for Land Use / Land Cover Mapping and Change Detection in the Rural Urban Fringe Area of Enschede City, The Netherlands. International Archives of Photogrammetry and Remote Sensing, 33, 993-998.

Nouri, H., Beecham, S., Anderson, S., \& Nagler, P. (2014). High Spatial Resolution WorldView2 Imagery for Mapping NDVI and Its Relationship to Temporal Urban Landscape Evapotranspiration Factors. Remote Sensing, 6, 580-602. doi:10.3390/rs6010580.

O'Connell, J., Connolly, J., Vermote, E. F., \& Holden, N. M. (2013). Radiometric normalization for change detection in peatlands: a modified temporal invariant cluster approach. International Journal of Remote Sensing, 34, 2905-2924. https://doi.org/10.1080/01431161.2012.752886.

Phompila, C., Lewis, M., Ostendorf, B., \& Clarke, K. (2015). MODIS EVI and LST Temporal Response for Discrimination of Tropical Land Covers. Remote Sensing, 7, 6026-6040. doi:10.3390/rs70506026.

Pigeon, G., Lemonsu, A., Long, N., Barrié, J., Masson, V., \& Durand, P. (2006). Urban thermodynamic island in a coastal city analysed from an optimized surface network. Boundary-Layer Meteorology, 120, 315-351. 
Pijanowski, B. C., Brown, D. G., Shellito, B., \& Manik, G. (2002). Using neural networks and GIS to forecast land use changes: a land transformation model. Computers, Environment and Urban Systems, 26, 553-575. https://doi.org/10.1016/S0198-9715(01)00015-1.

Rahman, M. A., Woobaidullah, A. S. M., Quamruzzaman, C., Rahman, M. M., Khan, A. U., \& Mustahid, F. (2016a). Probable Liquefaction Map for Purbachal New Town, Dhaka, Bangladesh. International Journal of Emerging Technology and Advanced Engineering, 6, 345-356.

Rahman, M. A., Mostafa Kamal, S. M., \& Maruf Billah, M. (2016b). Rainfall Variability and Linear Trend Models on North-West Part of Bangladesh for the Last 40 Years. American Journal of Applied Mathematics, 4, 158-162. doi: 10.11648/j.ajam.20160403.16

Rocha, A. V., \& Shaver, G. R. (2009). Advantages of a two band EVI calculated from solar and photosynthetically active radiation fluxes. Agricultural and Forest Meteorology, 149, 1560-1563.

Rouse, J. W., Haas, R. H., Deering, D. W., Schell, J. A., \& Harlan, J. C. (1974). Monitoring the vernal advancement and retrogradation (green wave effect) of natural vegetation. Technical Report, No E74-10676, NASA-CR-139243, PR-7. ID: 19740022555. Texas A\&M Univ.; Remote Sensing Center. College Station, TX, United States.

Sahebjalal, E., \& Dashtekian, K. (2013). Analysis of land use-land covers changes using normalized difference vegetation index (NDVI) differencing and classification methods. African Journal of Agricultural Research, 8, 4614-4622. doi:10.5897/AJAR11.1825.

Salam, M. A., Noguchi, T., \& Koike, M. (1999). The causes of forest cover loss in the hill forests in Bangladesh. GeoJournal, 47, 539-549.

Saleska, S. R., Didan, K., Huete, A. R., da Rocha, H. R. (2007). Amazon forests green-up during 2005 drought. Science, 318, 612.

Sesnie, S. E., Gessler, P. E., Finegan, B., \& Thessler, S. (2008). Integrating Landsat TM and SRTM-DEM derived variables with decision trees for habitat classification and change detection in complex neotropical environments. Remote Sensing of Environment, 112(5), $2145-2159$.

Shapla, T., Park, J., Hongo, C., \& Kuze, H. (2015). Agricultural land cover change in Gazipur, Bangladesh, in relation to local economy studied using Landsat images. Advances in Remote Sensing, 4, 214-223. http://dx.doi.org/10.4236/ars.2015.43017. 
Singh, R. P., Singh, N., Singh, S., \& Mukherjee, S. (2016). Normalized Difference Vegetation Index (NDVI) Based Classification to Assess the Change in Land Use/Land Cover (LULC) in Lower Assam, India. International Journal of Advanced Remote Sensing and GIS, 5, 1963-1970. doi: https://doi.org/10.23953/cloud.ijarsg.74.

Tucker, C. J. (1979). Red and photographic infrared linear combinations for monitoring vegetation. Remote Sensing of Environment, 8, 127-150. https://doi.org/10.1016/00344257(79)90013-0.

Van Leeuwen, W. J. D., \& Huete, A. R. (1996). Effects of standing litter on the biophysical interpretation of plant canopies with spectral indices. Remote Sensing of Environment, 55, 123-138. https://doi.org/10.1016/0034-4257(95)00198-0.

Wardlow, B. D., Egbert, S. L., \& Kastens, J. H. (2007). Analysis of time-series MODIS 250 m vegetation index data for crop classification in the U.S. Central Great Plains. Remote Sensing of Environment, 108, 290-310.

Xie, Y., Sha, Z., \& Yu, M. (2008). Remote sensing imagery in vegetation mapping: a review. $J$ Plant Ecol, 1, 9-23. https://doi.org/10.1093/jpe/rtm005.

Zaman, A. K. M. A. (2016). Precarious Periphery: Satellite township development causing socio-political economic and environmental threats at the fringe areas of Dhaka. Unpublished Paper. Department of Architecture, KU Leuven. https://doi.org/10.13140/rg.2.2.30067.32807.

Zar, J. H. (1999). Biostatistical Analysis. Department of Biological Sciences, Northern Illinois University. 4th Ed. New Jersey 07458, USA. Prentice Hall, Inc. Simon \& Schuster. ISBN 0-13-082390-2.

Zhou, N. Q., \& Zhao, S. (2013). Urbanization process and induced environmental geological hazards in China. Natural Hazards, 67, 797-810. doi:10.1007/s11069-013-0606-1. 